EGU21-20

https://doi.org/10.5194/egusphere-egu21-20

EGU General Assembly 2021

(c) Author(s) 2022. This work is distributed under

the Creative Commons Attribution 4.0 License.

\title{
The Variscan structure of the western Cantabrian Mountains (NW Spain) from ambient noise interferometry
}

\author{
Jorge Acevedo ${ }^{1}$, Gabriela Fernández-Viejo ${ }^{1}$, Sergio Llana-Fúnez ${ }^{1}$, Luis Pando ${ }^{1}$, Diego Pérez-Millán¹, \\ Mario Ruiz ${ }^{2}$, and Jordi Díaz ${ }^{2}$ \\ ${ }^{1}$ Department of Geology. University of Oviedo. Jesús Arias de Velasco, 33005, Oviedo, Spain (acevedojorge@uniovi.es) \\ ${ }^{2}$ Geosciences Barcelona, GEO3BCN-CSIC (former Institute of Earth Sciences Jaume Almera). Lluís Solé i Sabaris, 08028, \\ Barcelona, Spain.
}

The Variscan belt was formed as a consequence of the collision of two major continents, Laurasia and Gondwana, in the late Paleozoic. Nowadays, it constitutes the basement of the Iberian peninsula (Iberian Massif) and a large part of western and central Europe. In the NW of Spain, the convergence between Iberia and Europe in the Cenozoic originated the uplift of the Cantabrian mountains (CM). In its central sector, the erosion of the Mesozoic sedimentary cover during orogenesis led to the exhumation of the underlying Variscan basement in their western sector. The section of the Variscan belt that is currently exposed in the CM illustrates the transition from the internal zones of an orogen, in the west, to the external ones, to the east.

In order to acquire new passive data from this region, a portable seismic network consisting of 13 three-component broadband stations was deployed (GEOCANTÁBRICA-COSTA, doi:10.7914/SN/YR_2019). The recorded ambient noise seismic signal was cross-correlated using the phase cross-correlation (PCC) processing technique and the resulting daily cross-correlograms were stacked to obtain the empirical Green's function of the medium between each station pair. Since the vertical and the rotated horizontal components were processed, Rayleigh- and Lovewave group velocity dispersion curves were extracted. From these measurements, group velocity tomographic maps at periods between $2-14 \mathrm{~s}$ were calculated. Based on this set of tomographic maps, a final 3D S-wave velocity model $(2-12 \mathrm{~km})$ was derived from the joint inversion of the pseudo-dispersion curves created by extracting the Rayleigh and Love velocity values for each point of a dense grid.

Both the surface-wave and the S-wave velocity maps highlight essential elements of the surface geology of the area. The velocity pattern shows the boundary between two main geological domains: The Cantabrian Zone (CZ), to the east, which constitutes the foreland fold and thrust belt of the Variscan orogen; and the West Asturian-Leonese Zone (WALZ), to the west, the slate belt representing the low grade part of the internal zones. An E-W cross-section of the study area shows a high velocity unit to the west thrusting the lower velocity rocks of the $C Z$ at the transition between the WALZ and the CZ. 